\title{
Leigh's Disease in 3 Sibs of a Kuwaiti Family
}

\author{
Majedah Abdul-Rasoula Hanan Al-Qatan ${ }^{a}$ Hessa Habeeb $^{a}$ \\ Muneera Al-Adwani ${ }^{b}$ Maliha Al-Bouloshic ${ }^{c}$ Yousif Habeeb $^{c}$ Ali Mousac
}

Departments of a Pediatrics and ${ }^{b}$ Radiology, Farwania Hospital, and ${ }^{c}$ Department of Neurology,

Mubarak Al-Kabeer Hospital, Kuwait

\section{Key Words}

Leigh's disease - Subacute necrotizing encephalopathy • Autosomal recessive inheritance . Cytochrome c oxidase

\begin{abstract}
Objective and Importance: To describe Leigh's disease in 3 sibs of a Kuwaiti family. Case Presentation: Two brothers presented in early infancy with progressive neurological symptoms of hypotonia, delayed milestones and brisk reflexes. Investigations revealed metabolic acidosis, high serum and cerebrospinal fluid lactate. Magnetic resonance imaging (MRI) showed characteristic changes of Leigh's disease. The 3rd brother, who was asymptomatic initially, was investigated because of his family history and was found to have similar changes. Intervention: All children developed progressive neurological deterioration and persistent metabolic lactic acidosis, which was treated with sodium bicarbonate, and the 1st patient needed renal dialysis to control the acidosis. The 2 nd child was placed on vitamins and carnitine. Conclusion: The neurological deterioration was progressive in all 3 sibs, and they eventually died of respiratory failure despite ventilatory support. Since MRI changes are characteristic, MRI should be done to confirm the diagnosis.
\end{abstract}

Copyright $(2002$ S. Karger AG, Basel

\section{Introduction}

Leigh's disease (subacute necrotizing encephalopathy) is a progressive neurodegenerative disorder of infancy or early childhood. It is due to diverse biochemical defects of energy production and lactate accumulation. It presents in infants with feeding problems, seizures, respiratory problems, and cerebral and pyramidal signs. Family history is often positive. Elevated lactic acid, both in the serum and cerebrospinal fluid, is a frequent finding [1].

Multiple enzyme deficiencies have been described in Leigh's disease, including pyruvate dehydrogenase complex, nicotinamide adenine dinucleotide-coenzyme Q (CoQ) reductase (complex 1), cytochrome c oxidase (complex IV), succinate-CoQ reductase (complex II) and mitochondrial deoxyribonucleic acid $[1,2]$. These enzymes are deficient in multiple organs not only in the central nervous system [3]. Computed tomography (CT) as well as magnetic resonance imaging (MRI) have been useful in the diagnosis of the disease [4]. Hypodense well-circumscribed areas are seen in the basal ganglia and brain stem. The putamen is always involved as well as the globus pallidus, though to a lesser extent [4]. Mutations in SURF1 (a gene encoding a factor involved in the biosynthesis of cytochrome c oxidase) [5,6], mitochondrial adenozine triphosphatase (mtATPase 6) [2, 7, 8], and mitochondrial cytochrome c oxidase genes [9] were identified in patients with Leigh syndrome.

\begin{tabular}{ll}
\hline KARGER & ( ) 2002 S. Karger AG, Basel \\
1011-7571/02/0111-0046\$18.50/0 \\
$\begin{array}{l}\text { Fax +4161306 12 34 } \\
\begin{array}{l}\text { E-Mail karger@karger.ch } \\
\text { www.karger.com }\end{array}\end{array}$ & $\begin{array}{l}\text { Accessible online at: } \\
\text { www.karger.com/journals/mpp }\end{array}$
\end{tabular}

Dr. Majedah Abdul-Rasoul

Department of Pediatrics

Farwania Hospital, PO Box 284

13003 Safat (Kuwait)

Fax+956562 3963, E-Mail majedah2000@yahoo.com 


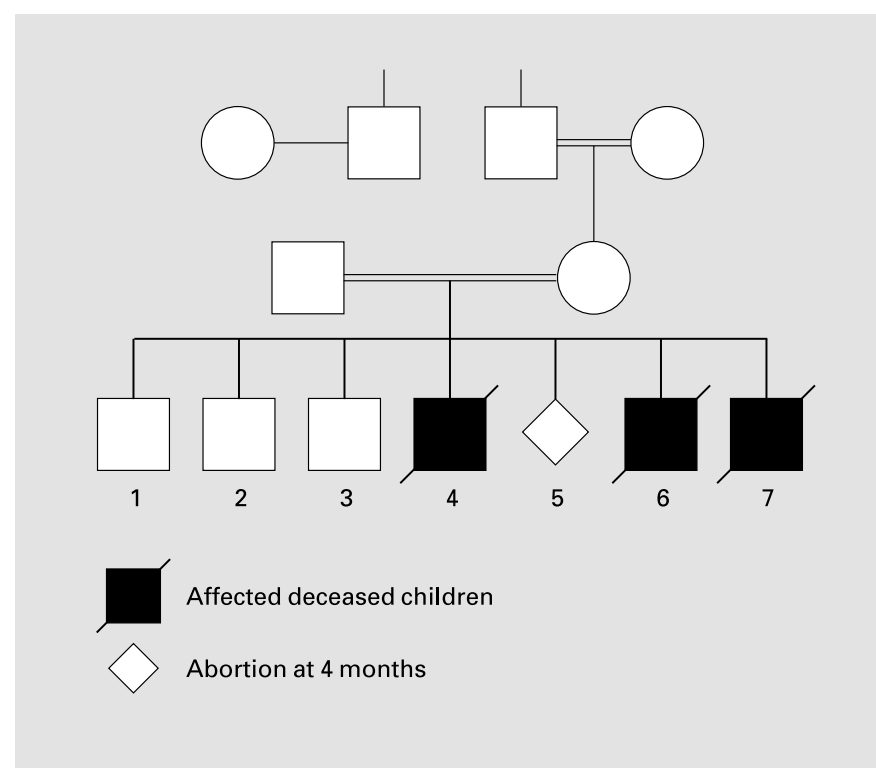

Fig. 1. Pedigree of the family with Leigh syndrome. Note: the consanguinity in the parents and the grandparents.

Herein, we describe 3 children within one family with Leigh's disease. To the best of our knowledge, this is the first case described in a Kuwaiti family.

\section{Case Report}

\section{Patient 1}

B.A. was seen at the age of 6 months for evaluation of developmental delay and frequent bruises since the age of 4 months. He was the 4th child to consanguineous (first-degree cousins) healthy parents, who had 3 older healthy sons (fig. 1). There was no history of any chronic diseases in the family.

At the initial assessment, he was found to be unable to sit, had poor head control, decreased tone, brisk reflexes, sustained clonus and persistent fisting. Biochemical investigation showed persistent metabolic acidosis and high lactate levels in the blood and cerebrospinal fluid. A CT scan showed mild brain atrophy. An MRI was ordered and showed extensive cerebral atrophy with high signals in the head of the caudate and lentiform nucleus (fig. 2b). A diagnosis of Leigh's disease was made based on the radiological and biochemical findings.

The child had progressive deterioration, with persistent metabolic acidosis that was only controlled with intravenous sodium bicarbonate and dialysis. A repeat MRI showed more extensive lesions, consistent with Leigh's disease. He developed respiratory difficulty, and died at the age of 8 months despite high parameter ventilatory support. Postmortem examination of the brain showed thick leptomeninges, cystic changes in the cerebral hemispheres and spongiform degeneration of the brain.
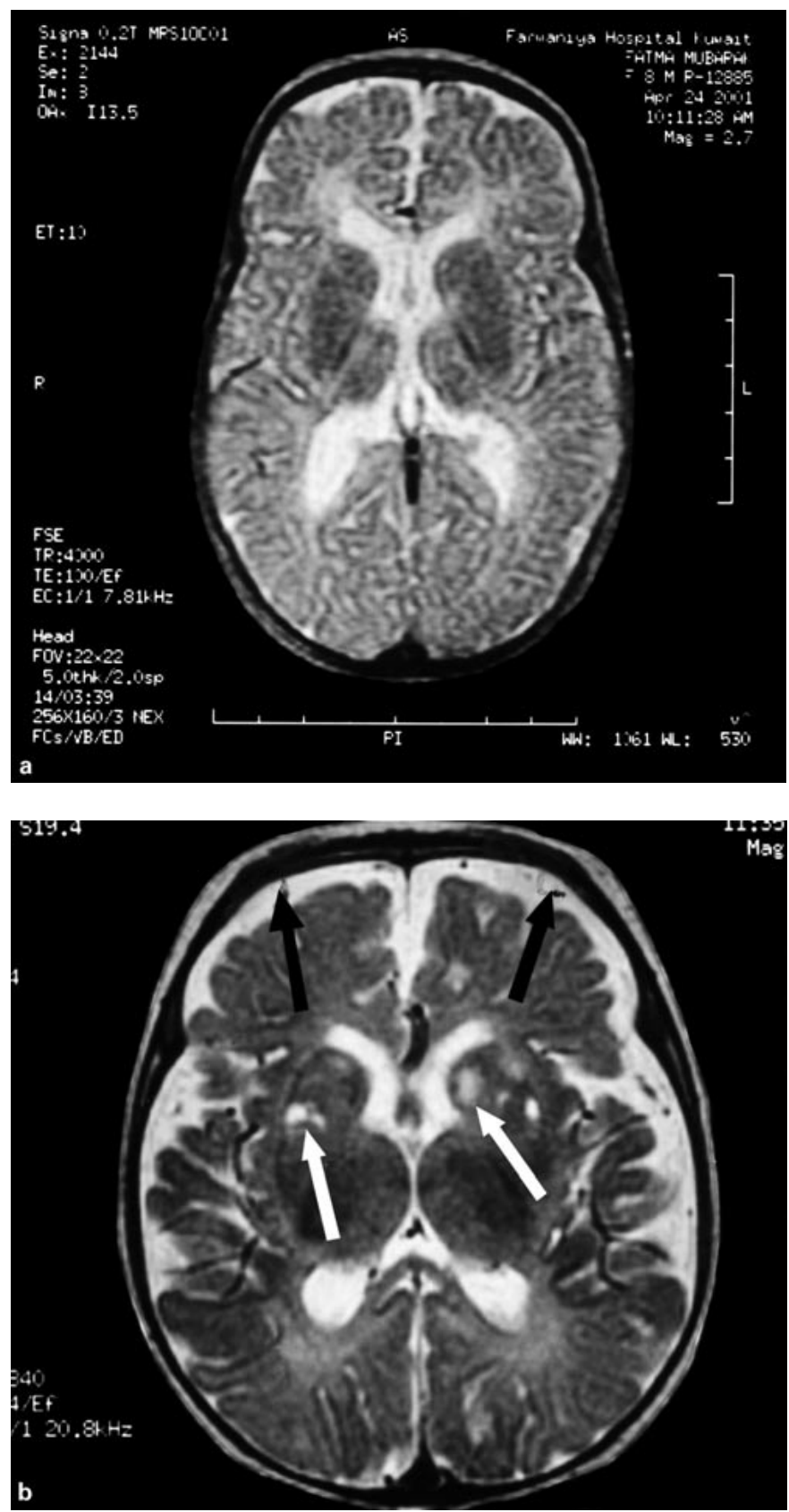

Fig. 2. a A normal MRI. b MRI of patient $1: T_{2}$ weighted images showing multiple small hyperintense foci (white arrows) seen in the head of the caudate nuclei and globus pallidi bilaterally associated with mild widening of CSF spaces (black arrows).

\section{Patient 2}

K.A. was the 6 th male child in this family. The fifth pregnancy ended by spontaneous abortion. He presented at the age of 3.5 months with developmental delay. He was found to have persistent metabolic acidosis and high serum and cerebrospinal fluid lactate. Cranial ultrasound showed cystic lesions in the germinal matrix on 
the right side and, to a lesser extent, on the left. An MRI showed areas of altered signals in the lentiform and caudate nuclei as well as the cerebral white matter bilaterally. Muscle biopsy showed fiber atrophy with increased lipids, and the activity of cytochrome $\mathrm{c}$ oxidase activity was deficient.

A diagnosis of Leigh's disease was made and he was started on carnitine, ubiquinone and vitamin supplements. At the age of 4 months, he had a generalized tonic-clonic seizure and was treated with phenobarbitone. EEG showed focal changes in the right cerebral region.

At the age of 7 months, he developed progressive cardiorespiratory failure, which was resistant to resuscitation. He died within $24 \mathrm{~h}$. The parents refused postmortem examination.

\section{Patient 3}

A.A., the youngest brother (the 7 th in the family), was seen at the age of 3 months because of episodes of bluish discoloration of the right limb. His development had been normal up to that age. Investigations which were done because of his family history showed elevated serum lactate level. MRI indicated hypodense foci of the caudate nucleus and globus pallidus, which supported the diagnosis of Leigh's disease. At the age of 5 months, he was markedly hypotonic with severe head lag, arched back, fisting of the hands, and spasticity and clonus of the lower limbs. His general condition progressed in a similar pattern to that of his brothers, and he died at the age of 1.7 years.

\section{Discussion}

Our patients had lactic acidosis, both in the serum and cerebrospinal fluid, together with the radiological features of Leigh's disease. Patient B.A. had a muscle biopsy, which was also positive for cytochrome c oxidase deficiency. The postmortem brain examination showed changes similar to those reported for the disease $[4,5]$. Parents did not allow autopsy for the other 2 children: hence histological examination of the brain is not available. The MRI changes in patient B.A. showed extensive cerebral atrophy with high signals in the caudate and lentiform nucleus. Similar changes, with less severity, were found in his sibs, most likely because they presented at an earlier age.

The disorder in this family is most likely of an autosomal recessive inheritance as evidenced from the pedigree chart of the family (fig. 1). These cases are the first reported in Kuwait; however, similar cases were described in Saudi Arabia [3].

In the past, the definite diagnosis of the disease was only possible at the time of postmortem examination. With the improved technology of CT scan and MRI $[4,5]$, the diagnosis of Leigh's disease can be made based on the radiological findings together with the clinical picture and the family history and postmortem examination is not needed. In Leigh's disease, well-circumscribed, symmetric areas of cystic necrosis in the basal ganglia and brain stem occur [4]. The persistent acidosis may be responsible for these changes in the brain [6]. Although similar radiological changes can occur with anoxia, hypoxia, CO poisoning and other metabolic diseases, clinical and laboratory findings can differentiate them from Leigh's disease. The clinical course is variable, as we have seen in our cases. In most cases, however, the prognosis has been poor with subacute progression leading to death within months.

The human cytochrome oxidase (COX) complex is found in the inner mitochondrial membrane [7]. It consists of many subunits. Its deficiency is associated with lactic acidemia and several phenotypic forms $[5,6]$. The most common form is that of Leigh syndrome, which is associated with a $80-90 \%$ decrease in COX activity, affecting all tissues [7]. This form, which is the most likely in our patients, is usually fatal, with death occurring between 6 months and 12 years [8]. The mutation is not found in the nuclear genes encoding COX subunits, but in SURF-1, a cofactor involved in COX biogenesis. More than 30 different mutations have been reported in SURF1 [5-9]. The clinical picture of SURF-1 mutation is that of moderate acidemia and the mutation involves all major tissues, the heart, lung, brain, kidneys and skin fibroblasts [10]. Mutations in the human gene corresponding to yeast $\mathrm{SCO} 1$ or $\mathrm{SCO} 2$ genes, which are also involved in the synthesis of COX, are associated with encephalopathy and hypertrophic cardiomyopathy as well as with severe acidemia. Mutations are identified mainly in the heart and skeletal muscles [10]. Mutation in the COX 10 gene, another gene in the COX group, is associated with moderate acidemia, ataxia, leukodystrophy and tubulopathy [11]. The gene for 'fatal infantile' COX and the infantile reversible COX are under investigation [12-17].

\section{Conclusion}

Leigh syndrome is a progressive neurological disease that presents in early infancy. The defect is in the COX complex. Multiple genetic mutations have been described, which explain the clinical variability described in the literature. Radiological changes in MRI are very characteristic, and postmortem examination is no longer needed for confirmation of the diagnosis. 


\section{References}

1 Vilarinho L, Maia C, Coelho T, Coutinho P, Santorelli FM: Heterogeneous presentation in Leigh syndrome. J Inherit Metab Dis 1997;20: 704-705.

2 Dionisi-Vici C, Seneca S, Zeviani M, Fariello G, Rimoldi M, Bertini E: Fulminant Leigh syndrome and sudden unexpected death in a family with the T9176C mutation of the mitochondrial ATPase 6 gene. J Inherit Metab Dis 1998; 21:2-8.

3 Dabbagh O, Brismar J, Gascon GG, Ozand PT: The clinical spectrum of biotin-treatable encephalopathies in Saudi Arabia. Brain Dev 1994;16(suppl)72-80.

4 Greenberg SB, Faeber EN, Riviello JJ, de Leon G, Capitanio MA: Subacute necrotizing encephalopathy (Leigh disease): CT and MRI appearances. Pediatr Radiol 1990;21:5-8.

5 Topcu M, Saatci I, Apak RA, Soylemezoglu F, Akcoren Z: Leigh syndrome in a 3-year old boy with unusual brain MR imaging and pathologic findings. Am J Neurol 2000;21:224-227.

6 Pequignot MO, Dey R, Zeviani M, Tiranti V, Godinot C, Poyau A, Sue C, DiMauro S, Abitol M, Marsac C: Mutations in the SURF1 gene associated with Leigh syndrome and cytochrome $\mathrm{C}$ oxidase deficiency. Hum Mutat 2001;17:174-181.

7 Robinson BH: Human cytochrome oxidase deficiency. Pediatr Res 2000;48:581-585.

8 Tiranti V, Hoertnagel K, Carrozzo R, Galimberti C, Munaro M, Granatiero M, Zelante L, Gasparini P, Marzella R, Rocchi M, BayonaBafaluy MP, Enriquez JA, Uziel G, Bertini E, Dionisi-Vici C, Franco B, Meitinger T, Zevian M: Mutations of SURF-1 in Leigh disease associated with cytochrome c oxidase deficiency. Am J Hum Genet 1998;63:1609-1621.
9 Carrozzo R, Tessa A, Vazguez-Memije MF, Piemonte F, Patrono C, Malandrini A, DionisiVici C, Vilarinho L, Villanova M, Schagger H, Federico A, Bertini E, Santorelli FM: The T9176G mtDNA mutation severely affects ATP production and results in Leigh syndrome. Neurology 2001;56:687-690.

10 Sue CM, Karadimas C, Checcarelli N, Tanji K, Papadopoulou LC, Pallotti F, Guo FL, Shanske S, Hirano M, De Vivo DC, Van Coster R, Kaplan P, Bonilla E, DiMauro S: Differential features of patients with mutations in two COX assembly genes, SURF-1 and SCO2. Ann Neurol 2000;47:589-595.

11 Wilson CJ, Wood NW, Leonard JV, Surtees R, Rahman S: Mitochondrial DNA point mutation T9176C in Leigh syndrome. J Child Neurol 2000;15:830-833.

12 Tiranti V, Corona P, Greco M, Taanman JW, Carrara F, Lamantea E, Nijtmans L, Uziel G, Zeviani M: A novel frameshift mutation of the mtDNA COIII gene leads to impaired assembly of cytochrome $\mathrm{c}$ oxidase in a patient affected by Leigh-like syndrome. Hum Mol Genet 2000;1:2733-2742.

13 Takahashi S, Makita Y, Oki J, Miyamoto A, Yanagawa J, Naito E, Goto Y, Okuno A: De novo mtDNA nt 8993(T-G) mutation resulting in Leigh disease. Am J Hum Genet 1998;62: 717-719.
14 Fujii T, Hattori H, Higuchi Y, Tsuji M, Mitsuyoshi I: Phenotype differences between $\mathrm{T} \rightarrow$ $\mathrm{C}$ and $\mathrm{T} \rightarrow \mathrm{G}$ mutation at nt8993 of mitochondrial DNA in Leigh syndrome. Pediatr Neurol 1998;18:275-277.

15 Chakrapani A, Heptinstall L, Walter J: A family with Leigh syndrome caused by the rarer T8993C mutation. J Inherit Metab Dis 1998; 21:685.

16 Van Erven P, Cillessen J, Eekhoff EM, Gabreels FJ: Leigh syndrome, a mitochondrial encephalomyopathy: Review of the literature. Clin Neurol Neurosurg 1987;89:217-230.

17 Makino M, Horai S, Goto Y, Nonaka I: Confirmation that a T-to-C mutation at 9167 in mitochondrial DNA is an additional candidate mutation for Leigh's syndrome. Neuromuscul Disord 1998;8:149-151.

18 Rahman S, Blok RB, Dahl HH, Danks DM, Kirby DM, Chow CW, Christodoulou J: Leigh syndrome: Clinical features and biochemical and DNA abnormalities. Ann Neurol 1996;39: 343-351.

19 Myers RE: A unitary theory of causation of anoxic and hypoxic brain pathology. Adv Neurol 1979;26:195-213.

20 De Vries DD, van Engelen BG, Gabreels FJ, Ruitenbeek W, van Oost BB: A second missense mutation in mitochondrial ATPase 6 gene in Leigh syndrome. Ann Neurol 1993;34 410-412. 